\title{
An Empirical Analysis on Industrial Organization Structure of Chinese Software Service Outsourcing
}

\author{
Jiawen Shen ${ }^{1 *}$, Heng $\mathrm{Li}^{2}$ \\ ${ }^{1}$ School of Economics and Management, University of Science and Technology Beijing, Beijing, China; ${ }^{2}$ Department of Building \\ and Real Estate, Hong Kong Polytechnic University, Hong Kong, China. \\ Email: jw627@sina.com
}

Received February $8^{\text {th }}, 2010$; revised March 10 ${ }^{\text {th }}, 2010$; accepted April $17^{\text {th }}, 2010$.

\begin{abstract}
The global service outsourcing industry has developed rapidly; but how about the software service outsourcing industry in China? Employing the combination research methodologies of field survey, literature research and analysis of the collected data from the survey questionnaire using the SPSS statistic software and its relativity tests, this empirical study analyzed the market structure and performance of Beijing software service outsourcing industry. Based on the SCP paradigm of the industrial organization theory, the conclusion revealed that the market concentration of Beijing software service outsourcing industry was on the low level. The industry possesses the characteristics of low risk, low profit and low product differentiation. There is an apparent trend that increasing profit occurs to the large scale service organizations. Low level price competition dominates the industry at present. The market performance of the industry is therefore low, resulting in the low average profit to most service companies; but the average ratal of these firms is on an upward trend year after year.
\end{abstract}

Keywords: Industrial Organization, SCP Paradigm, Software, Service Outsourcing, Industrial Structure, Empirical Analysis

\section{Introduction}

With the rapid development of information technology and increasing opening of trade environment, a new round of industry and economy transformation occurs on global scale, which is reflected by the formation of modern service industry, tech-concentrated manufacturing and more investment in $\mathrm{R} \& \mathrm{D}$. This change promotes the development of outsourcing. Nowadays, the global service outsourcing industries have been developing rapidly, and more and more companies are turning into "the company without walls". Saying "the world flattens", Thomas L. Friedman described vividly this phenomenon in his book, "The World is Flat".

The financial tsunami which was triggered by the subloan crisis of USA in 2008 had resulted in the serious impact on global economy. On the other hand, it has also made new opportunities for development of the global service outsourcing industry. Many multinational companies facing to re-shuffle have to reduce costs in order to preserve their core competencies, and meanwhile, try to outsource their non-core business. The international service outsourcing market will have a huge space for development. At the same time, with the consummation of market-directed economy system and the decline of transaction costs of the service outsourcing market, the domestic service outsourcing market is also about to form new space for development. In 2007, the global software and information service industry had reached the scale of 940 billion U.S. dollars, of which the United States accounted for $36.5 \%$; the European Union accounted for $27.7 \%$; Japan $9.5 \%$ and China $8.7 \%$. In 2007, China's software service industry had achieved the value of 583.4 billion Yuan, of which outsourcing software and services exports accounted for 10.24 billion U.S. dollars. [1] The software service outsourcing has been developing rapidly in many Chinese cities in recent years, which promoted the upgrading of the industrial structure and the transformation of economic development models. Focusing on the Beijing outsourcing industry of software service, this paper empirically analyzed the status of the industrial and organizational structure. It provided the useful results and directions to the future development of the Chinese service outsourcing industry.

\section{Literature Review}

With regard to the definition of service outsourcing, according to "the notification of Ministry of Commerce on 
the implementation of Qian Bai Si project on service outsourcing" issued in 2006 of China's Commerce Ministry, the service outsourcing is referred to the business of information system framework, application management and business process optimization, contracted to the outside service suppliers in order to reduce costs, optimize the industrial value chain and enhance the core competence. In the Business Dictionary, service outsourcing, which is generally based on the contract of agreed standards, costs and conditions, transfers the service originally performed by in-house staff to external organizations. According to GARTNER, the IT service market is divided into the discrete service and the service outsourcing; whereas the service outsourcing is further divided into information technology outsourcing and business process outsourcing.

The research of outsourcing service in economics can be summarized as follows. Firstly, it proposes the perspective of transaction cost such as the Coase's theory of transaction costs. Coase (1937), the leader of the field, first introduced the concept of transaction costs to the analysis of internal and external activities, and brought forward to that the number of transactions between manufacturers with service providers would be increased with the deepening of Socio-professional division of labor. If the marginal revenue of social division of labor is greater than the marginal growth of transaction costs, then the division of labor would be deepened to promote the improvement of manufacturing efficiency. Secondly, it proposes the perspective of the international division of labor such as the theory of comparative advantage, resource endowments theory. Thirdly, it proposes the perspective of economies of scale such as Krugman's new trade theory that the intra-industry trade of the division of labor benefits from the economies of scale. Fourthly, the perspective of company management, such as the theory of company's core competitiveness, supply chain and value chain theory.

Under the less market-oriented status, the service business such as the R \& D, information, logistics, operations, marketing, was supplied usually by the various departments of a company. With the development of specialization and the scale of economy, as well as the decline of market transactions cost, these services have now been gradually outsourced. Gradually, the service outsourcing industry is formed. The outsourcing improves the efficiency of resources allocation and the market value of social production. It strengthens the core competence of the outsourcing organization. The main objectives of the outsourcing company include to reduce operating costs, to improve the core competitiveness, to improve the level of international performance, to obtain the external resources, to improve the profit of business restructuring, to divestiture the business in difficulty management and to share the risks with others, etc.
On the research of industrial organization theory, according to the different theoretical basis and research methods and choosing a different focus, scholars proposed numerous ideas in different times. Harvard University advocated the structuralism of antitrust and anti-concentration, which is based on monopolistic competition theory, by the statistic methodology of empirical study, and focusing on market structure. Chicago University used company performance as a judging criterion. The theory is based on the competitive market and focuses on market performance of an organization. The new industrial organization theory advocated the behaviorism which objects unfair conducts and is based on the transaction cost theory by the deductive methodology of reasoning-based. [2] Market structure and market performance are the main fields of the Harvard Theory. It advocates that market structure rests with market conduct and that the market conduct rests with market performance, that is, $\mathrm{S} \rightarrow \mathrm{C} \rightarrow \mathrm{P}$. The SCP paradigm of the Harvard Theory established the basic analytical framework for the early theoretical studies of industrial organization. The Harvard Theory mainly puts the empirical studies on the relationship of market structure and performance, such as the Bain's concentration, concluding that the entry barriers were positively correlated with the profitability. The Chicago Theory focuses on the price conduct. The new industrial organization theory focuses on the company conduct.

The literature research over internet did not find the academic literature based on the industrial organization theory for the software outsourcing. It is perhaps due to the fact that the software service outsourcing is a new industry.

\section{Research Methodology and Data Sources}

Guided by the industrial organization theory and employing the qualitative and quantitative analytical method, the combination of theoretical research and questionnaire survey, the correlation test of statistical methods and the application of SPSS statistical analysis software, we surveyed 200 software service outsourcing companies based in Beijing. Sixty nine (69) questionnaires returned which formed the basis of our data analysis. The research revealed the overall status of software service outsourcing industry in Beijing.

The data retrieved from the following files: "the Report of China Software Industry Development Research 2008", "the Blue Book of Beijing Software Industry Development 2008", "the Statistical Communique of Beijing National Economic and Social Development in 2007", and the Statistics data of questionnaire to Beijing's service outsourcing firm in 2008.

From the industry organization theory point of view, it is the first time to exercise the methods of combination of the empirical research and the expanded SCP paradigm to 
the software service outsourcing industry at present.

\section{The Industry Organization State of Software Service Outsourcing in Beijing}

It is necessary to describe the industry organization status of software service outsourcing in Beijing before the SCP paradigm analysis of industry organization. According to the statistical result of the survey questionnaire and the relevant information, we analyzed the industry state from four aspects: industry overview, firm kinds, firm size, and human resource structure.

\subsection{Industry Overview}

An upward trend shows that the Beijing software service outsourcing industry contributes to the City's economy growth year after year. In 2007, the Beijing software industry had 241,000 employee and more than 5000 service companies. [3] According to the data published by the Beijing statistic bureau, Beijing's GDP in 2007 was 900.62 billion Yuan, of which 82.48 billion Yuan was contributed by the information transmission, computer services and software industry. In 2007, the total business income of Beijing software service industry was 125.2 billion Yuan, a 44.3 billion Yuan increase or a $28.8 \%$ growth over 2006. Its weight in Beijing's GDP increased from $2.6 \%$ in 2006 to $4.9 \%$ in 2007. [4] According to the statistics of the Beijing Customs and the Beijing Commerce Bureau, the export value of software by Beijing-based companies reached 459 million U.S. dollars in 2007. The rapid development of software service outsourcing industry promoted the optimization and upgrading of Beijing economic structure.

\subsection{Type of Service Companies}

According to the statistics analysis on survey questionnaire, the Beijing software services outsourcing industry made up of the wholly owned companies by foreign firms (accounting for 52\%), the foreign-controlled joint ventures (accounting for 14\%), the joint ventures controlled by Chinese (accounting for 12\%) and the Chinese-founded firms (accounting for 22\%).

According to the research results of the Japan Industry Economy Institute, which was also based on a survey conducted in 2007, the sub-contractors of Japanese information service outsourcing companies include the subsidiary of the Japanese companies which accounted for $37 \%$, the subsidiaries of another Japanese firms which accounted for $20 \%$ and the subsidiaries of overseas firms which accounted for $43 \%$ [5].

\subsection{Firm Scale}

According to the survey results, the firms that had 1000 5000 employees accounted for $12 \%$; the firms having
300 999 employees accounted for $23 \%$; the firms having 100 299 employees accounted for $26 \%$; and the firms that have no more than 100 employees accounted for $39 \%$. The data shows that the scale of the majority companies of Beijing service outsourcing industry was small, and there are not the large firms with global-scale competence. At present, Neusoft, which is the largest corporation of service outsourcing in China, has about 13,000 employees. But, there is not the service outsourcing firm that has more than 6000 employees in Beijing. The data from the study shows that the small-sized firms are the main part of the Beijing software service outsourcing industry. Those having 100-1000 employees account for about $49 \%$.

\subsection{Human Resource Structure}

For the software service outsourcing industry in Beijing, there is a rich reserve of human resource, a dense location of universities and research institutes in science and technology fields, a high degree of aggregation of industries, a large amount of employees with high quality and full features of stamina. The Beijing software service industry contained 241,000 employees in 2007. It is expected that this employee team will grow to 32 million by 2010 . From the aspect of education structure, the employees with undergraduate education accounted for more than $74 \%$, of which Master's degree or above accounted for $15 \%$. From the aspect of age structure, the employees under the age 40 accounted for $90 \%$, of which those under the age 29 accounted for $62 \%$; those between $30-39$-year-old accounted for 28\%. [4] Based on the analysis of survey questionnaire, we found that the technical staff accounted for $86 \%$ in the total number of staff of the Beijing software service outsourcing firms, of which project managers (PM) account for $7 \%$, system engineers (SE) accounted for $26 \%$ and programmers (PG) accounted for $53 \%$ of the total number of employees.

\section{Analysis of the Software Service Outsourcing Industry in Beijing}

The "Structure-conduct-performance" analysis paradigm (SCP paradigm) considers that the market structure determines the competition in an industry, the conduct of business strategy and the performance. The traditional industrial organization theory utilizes the statistic method of empirical analysis as its primary research methodology. Based on the presupposition that the industrial structure was given and that the existing differences among firms are the exogenous variable, it determines the Industrial competitive state, makes statistic cross-section observation on the actual conduct of both the industry and each individual firm, and then correlate the analysis results with the market performance of the firms. The new industrial organization theory adopts the research meth- 
odology of deductive reasoning. It considers that the traditional industrial organization theory over relies on empirical statistical analysis and lacks of theoretical basis and formal models on market analysis so that it is only suitable for statistic analysis in short term. It is necessary to penetrate the study of the conduct attributions of participants in economic activities in order to understand the reasons of the formation and change of industry structure. Our study described in this article is based on the expanded SCP paradigm for the empirical analysis of the Beijing software service industry.

\subsection{Market Structure Analysis}

Market structure is a concept of the relationship between market competition and market monopoly. Here, we studied the four qualitative criteria such as market concentration, entry and exit barriers, product differentiation and scale economy for quantitative and qualitative analysis of market structure of the Beijing software services outsourcing industry.

\subsubsection{Market Concentration}

Market concentration is a quantitative criterion of the market structure to measure the differences in number and related scale of the firms. The market concentration denotes the distribution of firm's relative size and the competition level of the industry. Following two parameters are commonly used:

the absolute concentration Rate $(C R n)$

$$
C R n=\sum_{i=1}^{n} X i / X
$$

and Herfindahl Hirschman Index (HHI)

$$
H H I=\sum_{i=1}^{n}(X i / X)^{2}
$$

( $X i / X$, a firm's market share).

$C R n$ indicates the concentration rate of the largest firms in the industry, but does not indicate the number and the scale proportion of all firms in the industry. Although $H H I$ is better than $C R n, H H I$ possesses some shortcomings in that the intuitive is poor, the weight of minor-firms is too small, and the data is difficult to collect. Here, we adopt the indicator of $C R 4$ and $C R 8$. The proportion of the four largest firm and the eight largest companies accounted for the total output of the industry.

The turnover of the Beijing software service industry was 125.2 billion Yuan in 2007 [3], of which 459 million U.S. dollars was from the software exports. Analysis of the data from the survey questionnaire revealed the eight largest firms in the Beijing software service outsourcing industry and the results of calculation for the Beijing software service outsourcing industry in 2007 are:

$$
C R 4=27.6 \%, C R 8=38.2 \% \text {. }
$$

According to the data, we can draw the conclusion that the concentration of the Beijing software services outsourcing industry is at the low level. According to the Bain classification and taking into the account of the number of software exporting firms in Beijing which was more than 200 in 2007, we concluded that the software services outsourcing in Beijing belonged to atom-type markets and was a fully competitive market, of which the scale economy was lower, so that the firms in the industry would be difficult to accumulate capital to carry out technology innovation and to form the core competence.

The reasons that resulted in the low concentration of Beijing software service outsourcing industry may lie in the following aspects: Firstly, the Beijing software service outsourcing industry was still at the stage of low level competition. The market was at the state of lower level equilibrium. The firms could not afford to build strong brands. So the industry concentration was low. Secondly, the Beijing software and service outsourcing industry is an emerging industry which is still in the initial development stage. The small and medium-sized firms are difficult to expand market rapidly at the stage, but easy to form a fully competitive industry structure, thereby affecting the market concentration. Thirdly, the diversification of market segments results in the decrease of the industrial concentration. As a result of the needs for the growing diversity of software service outsourcing industry, the firms providing software services businesses paid more attention to market segments and developed the differentiated products and services. The increase of market segments resulted in the reduction of market concentration.

\subsubsection{Analysis of Barriers to Entry and Hurdles to Exit}

- Analysis of barriers to entry

Barriers to entry refer to the degree that the existing firms of industry have market dominance in comparison with the firms that are potentially about to enter or have just entered the industry. Entry barrier is an important factor that affects the relationship between market monopoly and market competition in the industry. It is also a direct reflection of the market structure. The reasons for the formation of entry barriers include: economy scale, necessary capital and buried cost, product difference, absolute cost, policies and laws and the deferred reaction of existing firms.

About the entry barriers of Beijing software service outsourcing industry: First, there are no barriers to enter the administrative access control. The investment administration system has the approval power on the macrocontrol industries such as iron and steel industries; but for the software service outsourcing industry, the Government has introduced a number of policies to encourage the development of service outsourcing industry. Not only are there no policy entry barriers, but there are also many government incentives. Second, overall, technical 
barriers are lower to enter. Outsourcing services are knowledge-intensive industries but there is little difference in the enterprise management and marketing means. It is easy to make up through imitating and introducing talent. The R \& D centers and branches of multinational outsourcing services companies in Beijing have a great monopoly in their market segment. Many software service outsourcing firms, especially those minor-firms, have to be the taskmaster of software blue-collars. They have to face competition from a large number of potential entrants because they do not grasp the core technology. Third, for cost barriers, the start-up cost for a company is low. It is easy for potential entrants to find the starting point from the entrepreneurial company of tens thousands dollars to large-scale integration corporation of billions of dollars. Fourth, the dominant oligopoly firms do not come into being, so there are no androgenic barriers to enter the industry. Fifth, there is no ownership of discrimination to enter. When the private capitals and foreign capitals enter industries such as banks, petroleum and petrochemical, power and others, they will face many limits to get approval, but this is not the case for the existing service outsourcing industry. So much more capitals are attracted especially the foreign capital to enter the industry. In short, the barriers to enter the Beijing software service outsourcing industry are relatively low.

- Analysis of barriers for exit

Exit barrier refers to the price to be paid or cost to exit the industry, such as unused asset, exit cost, strategic impact, psychological factors, government restriction and the social obligation. Through the investigation, we discovered following issues for the Beijing software service outsourcing industry: First, the offices of most firms were leased. The investment for fixed assets is mainly concentrated in the office equipment such as computers. Therefore, the cost of unused assets is relatively low. Second, the majority of companies used the way of dispatch staff. So the resettlement cost of personnel is relatively low. Third, the strategic impact is medium due to the fact that most firms are wholly-owned or the joint ventures of multinational companies in Beijing. Exit will affect multinational corporations. Fourth, psychological factor play roles. Since the wage level is higher than the average level of the society, employees in the industry do not want to leave the industry. Fifth, the Government actively encourages service outsourcing industry due to its concern of the unemployment rate and the change in the pattern of economic development. There would be some restriction from the Government if it was to exit. In short, the barriers to exit of Beijing software service outsourcing industry are relatively low.

- Conclusion

Beijing software services outsourcing industry is relatively a low risk and low profit industry. According to the relationship matrix of barriers for entry and barriers for exit, location of Beijing software service outsourcing industry in the relationship matrix is as Figure 1.

From the company profits point of view, the high barriers to entry and low barriers to exit will be beneficial to the development of the Beijing software service outsourcing industry, which means the low-risk, high-profit, easy to accelerate and scale up of service outsourcing firms. While increasing the entry barriers will lead to the price distortions, it can prevent the small enterprises with low efficiency from entering the market so as to increase the industrial concentration. The whole industry thus gains access to scale economy, resulting in the decrease of cost of resources re-allocation. In addition, more entry barriers and product differentiation will improve the diversification of products with more heterogeneity and overall effectiveness of the community, thereby resulting in the naissance of many sub-industries.

\subsubsection{Product Differentiation}

Differentiated products or services affect the firms to control the market successfully. The software service outsourcing firms formed different business to meet different demands of consumers, which contains differentiated products and services. According to the questionnaire statistic, we analyzed the three indicators: the core business, customer distribution and the target market. The results are listed as follows:

First, looking from the aspect of the main business types, the firms primarily working on outsourcing of information services (IT0) accounted for $63.16 \%$; the firms working on business process outsourcing (BPO) accounted for $5.26 \%$; the firms mainly working on software development and sales accounted for $26.32 \%$; the firms mainly working on embedded product development and sales accounted for $2.63 \%$; and all other firms accounted for $2.63 \%$.

Second, looking from the aspect of customer industry differentiation, the IT industry accounted for $65.57 \%$; the financial industry accounted for $8.11 \%$; the telecommunications industry accounted for $8.11 \%$; the commerce industry accounted for $5.41 \%$; the advertising industry accounted for 2.7\%; and other industries accounted for $2.7 \%$.

\begin{tabular}{|c|c|c|c|}
\hline \multicolumn{2}{|c|}{} & \multicolumn{2}{c|}{ Barriers to entry } \\
\cline { 2 - 4 } & Low & High \\
\hline \multirow{3}{*}{ Barriers to exit } & High & $\begin{array}{c}\text { high risk, } \\
\text { low profit }\end{array}$ & $\begin{array}{c}\text { high risk, } \\
\text { high profit }\end{array}$ \\
\cline { 2 - 4 } & Low & $\begin{array}{c}\text { low risk, } \\
\text { low profit }\end{array}$ & $\begin{array}{c}\text { low risk, } \\
\text { high profit }\end{array}$ \\
\hline
\end{tabular}

Figure 1. Relationship matrix of barriers for entry \& exit 
Third, looking from the aspect of target markets differentiation, the firms whose outsourcing contracts were mainly from Japanese companies accounted for $52 \%$; the firms whose outsourcing contracts were mainly from US companies accounted for $35 \%$; the firms whose outsourcing contracts were from EU companies accounted for $7 \%$; and the firms whose outsourcing contracts were from companies located in Hong Kong accounted for $6 \%$.

Through the comprehensive analysis of the above data, we could find that the software service outsourcing firms in Beijing mainly focused on the ITO business from Japan and USA. The product differentiation was indistinctive on a whole.

\subsubsection{Scale Economy}

Scale economy is an economic phenomenon, in which the expansion of production scale of firms conduces to the constant improvement of product production efficiency, therefore achieving the economic goals. Returns to scale is referred to that the output change is proportionally related to the change of input factors, including increasing returns to scale, constant and decreasing. Generally, the approach to distinguish returns to scale is as follows: Two input factors have increased in $\lambda$-fold, output will increase in h-fold, that is:

$$
h Q=f(\lambda K, \lambda L)
$$

If $h=\lambda$, the constant returns to scale; if $h<\lambda$, the scale of diminishing returns; if $h>\lambda$, the increase returns to scale. Here we use the correlation test of statistic, the application of statistical analysis software SPSS, to test the correlation between firm scale and firm output of the Beijing software service outsourcing industry.

- Test method

Correlation analysis is a statistical method to examine the relation between the different variables; whereas the correlation coefficient measures the linear relationship and direction between two variables. The linear correlation analysis is a mathematics tool involved in the correlation coefficient to study the linear of the two variables. Due to the fact that sampling error always exists in sample data, the sample correlation coefficient between two variables, if not zero, must pass the test. The assumption of the test is that the correlation coefficient between the two variables is zero. In general, assuming the probability $\mathrm{P}$ is true when the domain value is $5 \%$, if $\mathrm{P}<5 \%$, the original hypothesis false, or accept the original hypothesis.

- Indicators and data source

Based on the characteristics of software service outsourcing industry, the total number of employees in any firm is generally the main indicators to measure the firm scale. The study takes the number of employees of outsourcing firms as dependent variable, and takes the turnover which is the key indicators of a firm's output as independent variables. Due to the fact that the service outsourcing is an emerging industry, it is difficult to col- lect its time-series data but the cross-section data is relatively easy to obtain. According to the 2008 survey questionnaire, we take the statistic on the number of employees of firms and their turnovers in 2007, through the statistical analysis software SPPS for the correlation test on the data.

- Descriptive Statistics is shown as Table 1

- T Test of single sample is shown as Table 2

From Table 2, the result of $\mathrm{T}$ test is as follows, $\mathrm{df}=58$, $\mathrm{P}=0<0.05$, so the sample is statistically significant.

- Result of Correlation test is shown as Table 3

From Table 3, The result of correlation test shows that the Pearson correlation coefficient is 0.455 and $\mathrm{P}=0$. Overall, the assumption of zero correlation coefficient between the two variables is rejected. Significant correlation occurs on the 0.01 level (bilateral). Therefore, a strong positive linear correlation exists between the firm employee number and the firm turnover.

Table 1. Descriptive Statistics of Employee number and Turnover of firms

\begin{tabular}{cccc}
\hline & Mean & Standard & N \\
\hline Employee number & 476.9 & 869.797 & 58 \\
Turnover & 4764.41 & 7498.641 & 58 \\
\hline
\end{tabular}

Table 2. T Test of single sample

\begin{tabular}{|c|c|c|c|c|c|}
\hline & \multicolumn{5}{|c|}{ Test Value $=0$} \\
\hline & & & & \multicolumn{2}{|c|}{$\begin{array}{l}95 \% \text { Confidence Interval } \\
\text { of the Difference }\end{array}$} \\
\hline & $\mathrm{t} \quad \mathrm{df}$ & $\begin{array}{c}\text { Sig. } \\
\text { (2-tailed) }\end{array}$ & $\begin{array}{c}\text { Mean } \\
\text { difference }\end{array}$ & Lower & Upper \\
\hline Employee & 4.36958 & 0.000 & 360.78571 & 195.2981 & 526.2733 \\
\hline Turnover & 4.57258 & 0.000 & 4583.7568 & 2574.4719 & 6593.0417 \\
\hline
\end{tabular}

Table 3. Result of Correlation test

\begin{tabular}{cccc}
\hline & & $\begin{array}{c}\text { Employee } \\
\text { number }\end{array}$ & Turnover \\
\cline { 2 - 4 } $\begin{array}{c}\text { Employee } \\
\text { number }\end{array}$ & Pearson correlation & 1 & $0.455^{* *}$ \\
& Significant (Bilateral) & & 0 \\
& $\mathrm{~N}$ & 58 & 58 \\
\hline Turnover & Pearson correlation & $0.455^{* *}$ & 1 \\
& Significant (Bilateral) & 0 & 58 \\
& $\mathrm{~N}$ & 58 & 5 \\
\hline
\end{tabular}

**. Significant correlation on the 0.01 level (bilateral) 
- Conclusion

Through the above correlation test, it can be judged: The scale economy of software service outsourcing industry in Beijing was taking on the significant increasing returns to scale, with which the firm earning grows with its production expansion and the increasing of firm earning in turn promotes the firm production expansion. The different scales of production will lead directly to the differences in economic and social benefits. According to the statistic analysis of questionnaire, the result shows that the firms whose turnover in 2007 was more than 100 millions Yuan accounted for 12\%; the firms with 10 100 million Yuan turnover accounted for 63\%; the firms with less than 10 millions turnover accounted for $25 \%$ of the total samples, increasing returns to scale. Through the questionnaire survey on the software service firms in Beijing, we found that the average employee number is 476 persons per firm. Therefore, it should be encouraged that the Beijing software service outsourcing firms carry out mergers, restructuring and integration. To improve scale economy of the industry, it is also important to speed up the formation of large groups and software outsourcing service outsourcing industry alliance.

\subsection{Analysis of Market Conduct}

Market conduct refers to that the firm takes adjustment actions to meet market requirement to achieve its stated objectives. A firm's market conduct mainly includes market-competitive conduct and market co-ordination conduct. Market-competitive conduct includes the pricing conduct with the characteristics of controlling and influencing price, mergers and acquisitions conducts with the characteristics of property right change and organization adjustment, sales promotion conducts with the purpose of enhancing competitiveness and expanding market, as well as advertising, research and development, and so on. Market coordination conduct mainly includes cooperate competitive behavior such as firms strategic alliances.

The market-competitive conduct of the Beijing software service outsourcing industry could be divided into three types: First, R \& D centers established in Beijing by multinational outsourcing services corporations whose main businesses are from the parent corporations. They basically do not participate in market-competition. Second, the branches opened in Beijing by the multinational corporations. They are mainly engaged in the business of the China market. Due to the high entry barriers such as technology, capital, brand, performance, these branches keep the oligopoly in the market segments and have much more competition advantage than domestic firms. Third, the Chinese firms which are engaged in overseas service outsourcing business. Most of them are wholly foreign-owned and joint-venture; some are subsidiary of institutes; and a few of private enterprises. These firms mainly participate in the international market-competi- tion of service outsourcing by taking the advantage of the large amount of high-quality, inexpensive software talents in Beijing. Due to the considerations of the technical control by the multinational corporations, the internalization of core technology is becoming clear with characteristics of the processing trade of low-tech and labor-intensive, while increasing the outsourcing of labor-intensive and low technology content, for example, the outsourcing projects from Japanese firms are generally the sub-modules which were disassembled basically by the general contractor through systematic design and structure analysis. Due to the lack of core technology, many Beijing's service outsourcing companies have to be the passive sub-contractors under the general contractor of overseas software service outsourcing, and are in the embarrassment position of taskmasters of the software blue-collar. Therefore, the market competition was so high. The pricing becomes an issue in the throat-cutting competition, which often adopts the head-count method that is based on the quoted labor costs in order to earn the low profit via the salary difference between the domestic market and foreign market.

From the aspect of pricing conduct, the low industrial concentration led to the full competition conduct. The present pricing is primarily controlled by the overseas contractors who generally denominate the market as they are attracted by the low labor costs. At present, the conduct of Beijing service outsourcing enterprises to improve the price competitiveness mainly reflect in hightech qualification, industry qualification certification and management certification. Based on the statistic of the questionnaire, in the Beijing software service outsourcing industry, the firms that have high-tech certification accounted for $83 \%$; the firms that have CMMI certification accounted for 33\%; the firms having CMM certification accounted for $43 \%$; the firms having ISO20000 certification accounted for $8 \%$; the firms having BS7799 certification accounted for 3\%; the firms having ISO27001 certification accounted for $16 \%$; and the firms having 2-soft certification accounted for $8 \%$. According to the statistic data of the Beijing software and information promotion centre, the combined numbers of firms that got the CMM/CMMI certifications were 152 in 2007, accounting for $24.9 \%$ and thus becoming No. 1 in the country; the numbers of firms that got the ISO20000 certification were 7 in the same year, accounting for $50 \%$ in the country; the firms having obtained the ISO27001 certification added up to 22 , accounting for $21.5 \%$ in the country. These data shows that the Beijing software service firms improve the price competitiveness through strengthening enterprise management certification.

Overall, the market conduct of the Beijing software service outsourcing has more, low level price competition, but uses few of non-price competition strategy. Looking from the aspect of mergers acquisitions conduct, 
although the Beijing government encourages mergers acquisitions, industry restructuring and the alliances, there have not been any firms or unions formed in the Beijing software service outsourcing industry with international competitiveness until now.

\subsection{Analysis of Market Performance}

Market performance reflects the ultimate economic successes such as the price, firm scale, production capacity, cost, profit, production quality, varieties and technology progress, which is the result of the given market conduct in the given market structure. The market performance indicates the market efficiency on resources allocation. The scholars represented by Bain advocated the financial indicators; whereas Lerner and other scholars preferred to the market power indicators. There are analysis indicators such as profit ratio, Bain index, the efficiency of resource allocation, Lerner index, rate of return, Tobin's $\mathrm{q}$ ratios and so on. Here, we adopt the indicators of the profit ratio and the ratal of firms to quantitatively analyze the market performance of the Beijing software service outsourcing industry.

\subsubsection{Analysis of Firm Profit Ratio}

Based on the survey results obtained from the Beijing software service outsourcing firms, we carried out the statistic analysis on the firm profit ratios in 2005, in 2006, and in 2007, respectively, using the SPSS statistic analysis software. The statistical results are described as Table 4.

From Table 4, the analysis result shows that the average profit ratio of the Beijing-based software service outsourcing firms dropped down from $17.05 \%$ in 2005 to $6.39 \%$ in 2007 . It could be explained by the fact that the competition in the industry was becoming fierce year after year, which led to the decline of profit ratio on market performance. The reasons maybe lie in: Firstly, the market concentration of industries was also dropping year after year, resulting in the change of the pricing conduct, further leading to the decline of profit ratio. Secondly, due to the appreciation of the RMB exchange rate in recent years, the competitive advantage of the Beijing software service outsourcing industry was weakened, resulting in the decrease of the profits of the service outsourcing firms that take the foreign exchange as their major settlement payment. In addition, according to "the China Statistic Yearbook", the average cost-profit ratio of all state-owned, large-size companies of the country is $7.43 \%$ in 2007 . Therefore, the profit ratio of the industry should be improved because the software and information service outsourcing is an emerging industry. If the profit ratio of the industry was lower than average profit ratio of the society for a long time, it would be detrimental to the effective concentration and configuration of resources.

\subsubsection{Analysis of Firm Ratal}

Still based on the survey results obtained from the software service outsourcing firms in Beijing, we carried out the statistic analysis on the firm's ratal in 2005, in 2006, and in 2007, respectively, by SPSS statistic analysis software. The results are displayed as follows:

From the statistical results in the Table 5, we can see that the average firm ratal of Beijing software and information services outsourcing industry showed an upward trend year after year. The average ratal was 1,523,700 Yuan every firm in 2005; it became 2,037,100 Yuan every firm in 2006 and 2,491,900 Yuan every firm in 2007. From the calculated data, it could be seen that the ratal growth rate was $33.69 \%$ in 2006 and $22.32 \%$ in 2007 . Therefore, we could draw following conclusions: Although the average profit ratio of the industry was declining, the average ratal of the firms was increasing year after year. The reason is that industry output (turnover) was growing and the industry scale was expanding rapidly.

\section{Conclusions}

Based on the SCP paradigm of the industrial organization theory, the study empirically analyzed the criteria of market structure, market conduct and market performance of the software service outsourcing industry in Beijing through the field survey, literature search, making use of the SPSS statistic software and its relativity tests. Following conclusions can be drawn from the study:

Firstly, on the aspect of market structure, the market concentration of software service outsourcing industry in Beijing is very low at present. The barriers to entry and exit are relatively low and belonging to the industry of lower risk and lower profit. The product differentiation is not high. It mainly focuses on the ITO business from the

Table 4. Descriptive Statistics of profit ratio

\begin{tabular}{ccccc}
\hline & $\mathrm{N}$ & \multicolumn{2}{c}{ Mean } & $\begin{array}{c}\text { Standard } \\
\text { Deviation }\end{array}$ \\
\hline Year & Statistics & Statistics & $\begin{array}{c}\text { Standard } \\
\text { error }\end{array}$ & Statistics \\
\hline 2005 & 37 & 17.05 & 2.94 & 17.883 \\
2006 & 44 & 6.55 & 4.564 & 30.271 \\
2007 & 48 & 6.39 & 6.896 & 47.78 \\
\hline
\end{tabular}

Table 5. Descriptive Statistics of firm ratal

\begin{tabular}{ccccc}
\hline & N & \multicolumn{2}{c}{ Mean } & $\begin{array}{c}\text { Standard } \\
\text { Deviation }\end{array}$ \\
\hline Year & Statistic & Statistic & $\begin{array}{c}\text { Standard } \\
\text { error }\end{array}$ & Statistic \\
\hline 2005 & 39 & 152.37 & 39.642 & 247.563 \\
2006 & 44 & 203.71 & 46.829 & 310.629 \\
2007 & 47 & 249.19 & 61.568 & 422.091 \\
\hline
\end{tabular}


Japanese and American companies. The industry shows increasing returns to scale, but the scale economy of the industry has still not been incarnated.

Then, on the aspect of market conduct, the low market concentration led to the fierce market competition. Except for the R \& D centers and branches owned by the multinational companies that have strong pricing power, all local software service outsourcing firms are involved in the fierce market competition as demonstrated specifically by the very low industry concentration and the very low average scale of firms. The price competitiveness of the whole industry is still weak and the price-competitive conduct seems to be disordered. The non-price competition strategy is not becoming prevalent. Super powerful companies with internationally recognized competence have still not existed yet at present in the Beijing software service outsourcing industry.

Finally, on the aspect of the market performance, the firm profit rate of the Beijing software service outsourcing had been declining year after year. The average profit rate is low, but the average firm ratal shows upward trend. The reasons of this phenomenon might primarily lie in the low level of price-competition caused by the low industry concentration and the rapid expansion of the in- dustry scale.

\section{Acknowledgements}

Author would like to thank Prof. Jingfu Bai of University of Science and Technology Beijing, and Dr. Jim Zhang of JZMed Inc of New York in USA for their valuable advices during preparation of the paper.

\section{REFERENCES}

[1] China Software Association, etc., "The Research Report of China Software Industry Development in 2008," China, 2008.

[2] X. F. Niu, "The Evolvement and Development of Western Industrial Theory," Economy Research, Vol. 3, 2004, pp. 116-123.

[3] Beijing Statistics Bureau, "Statistical Bulletin National Economic and Social Development of Beijing in 2007," Beijing Statistics Bureau, Beijing, 2008.

[4] Beijing Software and Information Services Promotion Centre, etc., "The Blue Book of Beijing Software Industry Development in 2008," China, 2008.

[5] E. Fukuura, "The International Outsourcing of Japan Companies," Journal of Industry Economy, Vol. 3, 2008. 